vinguishing between charge transfer and sxcitation transfer processes in radiation chemistry.

\section{T. Morrow}

G. A. SALMON

University of Leeds,

Cookridge High Energy Radiation

Research Centre,

Cookridge Hospital, Leeds.

Institute of Chemical Physies,

E. L. Frankevich

Academy of Sciences,

Vorobyevskoye chaussee 2-b,

Moscow, V-334, USSR.

Received June 21, 1908.

${ }^{1}$ McCollum, J. D., and Nevitt, T. D., US Tech. Rep., ASD-TDH-63-616 (1963).

${ }^{2}$ Kemp, T. J., Roberts, J. P., Salmon, G. A., and Thompson, G. F., Proc. Second Tihany Symp. Radiat. Chem., 333 (Akademiai Kiado, Budapest, 1967).

s Dainton, F. S., Salmon, G. A., Morrow, T., and Thompson, G. F., Chem. Comm., 326 (1968).

4 Talrose, V. L., Actions Chimiques et Biologiques des Radiations (edit. by Haissinsky, M.), 11, Ch. 2 (Academic Press and Masson et Cie, Paris, 1967).

- Freeman, G. R., J. Chem. Phys., 39, 1580 (1963).

- Freeman, G. R., and Fayadh, J. M., J. Chem. Phys., 43, 86 (1965).

('handross, E. A., Longworth, J. W., and Visco, R. E., J. Amer. Chem. Soe. 87,3257 (1965).

\section{Bioholography-a New Model of Information Processing}

IT is well known that the principles of wavefront reconstruction or holography ${ }^{1,2}$ apply also to wave phenomena other than light. I have shown ${ }^{3-5}$ that holograms can be produced with ultrasonic waves, and have recently suggested (refs. 6 and 7 and my unpublished results) that some biological information processes can be interpreted on this basis.

It has been known for many years that bats, dolphins, whales and porpoises use ultrasonic echo location ("sonar") for hunting and orientation in the dark. It seems, how ever, that they have capabilitios far exceeding conventional echo location. No satisfactory explanation has yet been offered for the fact that they can distinguish between targets of different shapes. They notice the qualities of the target; is it food, or should it be avoided ? 'They know whether bars in their way are horizontal or vertical. They can discriminate between their own signal and those emitted at the same time by their companions, though the frequency of the pulses is the same. Moreover, the processed signals may be as much as 2,000 times fainter than the background noise.

This suggests strongly that the animals perceive not, only the amplitude but also the phase of the ultrasound waves, which they can discriminate by using a coherent background as reference; in other words, they are using the principle of holography. Evidence for the coherent background has been found by Aryapetians ${ }^{8}$, who did not, however, realize that this was the key for these capabilities of the animals. When the bat emits an ultrasonic pulse of a certain frequency, at the same time the part of the brain which ordered the pulse to be emitted sends information on this to a second part of the brain where the ultrasound information is received and processed, and I think that the information sent by the first part of the brain to the second is the coherent reference background.

Furthermore, histological examination ${ }^{2}$ shows that this receiving and associating part of the brain has a structure which looks like an assembly of minute dipoles. This suggests binary digital processing, which is known to play an important part in processing biological information, and makes it plausible that the bats are using a holographic principle in interpreting the data supplied by the dipole-shaped receptors.

This explains the striking abilities of bats. They can distinguish shapes, and orientation in three dimensions because holography allows a geometrical interpretation of a received soundwave structure. They are not disturbed by the pulses emitted by their companions, because they use only their own signal as reference. By Gabor's holographic principle, if $A$ is the reference amplitude and $a$ the signal amplitude, the resultant amplitude which the dipoles are recording is

$$
\left(A^{2}+a^{2}+2 A a \cos \varphi\right)^{1 / 2}
$$

where $\varphi$ is the phase angle between the reference wave and the signal wave. $A^{2}$ is uniform, the second term $a^{2}$ is negligibly small. The information is carried by the last term, and is amplified by the large factor $A$. Indeed, it was found that bats are increasing only their own reference or background amplitude when the noise level is high, without increasing the intensity of their emitted pulses.

To back up our bioholographic concept, I have made a model of the bat's brain, operating in water at about $1 \mathrm{Mc}$, so that the wavelength shall be of the same order as that of hunting bats. The resulting ultrasound holograms were recorded on sono-sensitive photographic plates. When scanning these with a microdensitometer we obtained records which show a remarkable similarity to EEG records. (I do not wish to suggest, of course, that this is any proof of EEG curves arising by some holographic process.) From these, images may be reconstructed; for example, by using Goodmann's ${ }^{10}$ digital reconstruction technique.

There is reason to believe that the bioholographic concept is not restricted only to bats and other echolocating animals. It may well be that even in the human memory the data are stored in some holographic form. This might explain such psychological phenomena as the "dominance principle". Assume that somebody is angry, and we want to calm him, saying "don't be angry !" $\mathrm{He}$ gets even more angry, because the idea "be angry" is stored in holographic form, like a filter, which suppresses the "don't".

RSRT Ultrasonic Laboratory,

Paur Greguss

Budapest. Hungary.

1 (rabor, 1)., Nature, 161, 777 (1948).

2 (iabor, 1), Proc. Roy. Soc., A, 197, 455 (1949).

3 (ireguss, P., Second Nat. Conf. Vltrasonics, Praha (1965).

4 fireguss, P., Symp. Techniques in Appl. Photog., London (1965).

${ }^{5}$ Greguss, P., Research Film, 5, 330 (1965).

' Greguss, P., Lecture at Soc. Electronic Eng., Budapest (1967).

7 Greguss, P., Magyar Fizikai Blyoirat, 16, No. 6 (1968).

8 Aryapetians, E. S., and Konstantinov, A. I., Vaprosy Bioniki, 445 (196i).

"Aryapetians, E. S., Lecture at Soc. Electronic Eng., Budapest (1967).

10 froodmann, J. W., First Intern. Symp. Acmustical Holography, Huntington Beach (1967).

\section{Changes in Structure of Human Bone with Age}

THE pliability of human bone decreases with increasing age, and the incidence of bone fracture increases after about 35 years of age. These changes indicate that some structural changes occur in bone over a lifetime. Much work has been done on the correlation betwoen the histological components of bone and its physical properties, and their variation with age, but contradictory conclusions have been drawn ${ }^{1,2}$. No attempt seems to have been made to correlate the physical properties of bone with the physical and chemical nature of bone mineral, although it has been claimed that fracture occurs chiefly at "cement lines". Because the chemical nature of bone mineral, that is apatite, does not undergo any appreciable change during a lifetime, it can be inferred that the changes probably 